\title{
Knuckle Pads Versus Gottron's Papules: Making a Differential Diagnosis
}

\author{
Ester Pereira $^{\mathrm{a}, \mathrm{d}}$, Paula Estanqueiro ${ }^{\mathrm{b}}$, Oscar Tellechea $^{\mathrm{c}}$, Manuel Salgado ${ }^{\mathrm{b}}$
}

\begin{abstract}
Knuckle pads, circumscribed thickening of the skin over the finger joints, most often occur in teenagers and young adults and should be included in the vast differential diagnosis of cutaneous lesions of the hands and feet. Their recognition is essential for an adequate diagnosis and posterior orientation. We present a case report of a patient with characteristic lesions initially confounded with Gottron's papules.
\end{abstract}

Keywords: Knuckle pads; Gottron's papules

\section{Introduction}

Knuckle pads most often occur in teenagers and young adults and should be included in the vast differential diagnosis of cutaneous lesions of the hands and feet. Confusion with cutaneous manifestations of rheumatologic diseases, like rheumatoid nodules or Gottron's papules, may occur. Their recognition is essential for an adequate diagnosis and posterior orientation.

\section{Case Report}

A 13 year-old caucasian boy presented with various erythematous hyperkeratotic plaques on the extensor surfaces

\footnotetext{
Manuscript accepted for publication November 15, 2012

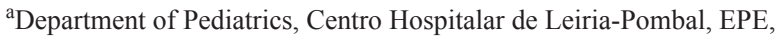
Portugal

${ }^{\mathrm{b}}$ Hospital Pediatrico Carmona da Mota, Centro Hospitalar e

Universitario de Coimbra, EPE, Portugal

${ }^{c}$ Department of Dermatology, Centro Hospitalar e Universitario de Coimbra, EPE, Portugal

${ }^{\mathrm{d}}$ Corresponding author: Ester Pereira, Centro Hospitalar de

Leiria-Pombal, EPE, Rua das Olhalvas Pousos, 2410 - 197 Leiria,

Portugal. Email: esterpmnpereira@gmail.com

doi: http://dx.doi.org/10.4021/jmc980w
}

of both hands, well-circumscribed, non-tender, overlying metacarpophalangeal, proximal interphalangeal and distal interphalangeal joints that appeared 2 years ago (Fig. 1, 2). They had slowly growing and varied in size between 0.5 $1.8 \mathrm{~cm}$. There weren't no other cutaneous lesions, namely on the feet, neither palmoplantar hyperkeratosis. The muscle strength examination was normal and he practiced sport in a regular basis (football) without any limitation. Personal and familiar antecedents were unremarkable, with no history of hearing loss. Initially, the diagnosis of Gottron's papules was considered and an analytical evaluation was performed, revealing normal whole blood count, erythrocyte sedimentation rate $(9 \mathrm{~mm} / \mathrm{h})$ and C-reactive protein $(5.4 \mathrm{mg} / \mathrm{L})$ and mildly elevated creatine phosphokinase ( $223 \mathrm{U} / \mathrm{L}$, normal 38 - $174 \mathrm{U} / \mathrm{L}$ ). The adolescent was referred to a Pediatric Rheumatologist who, in collaboration with a Dermatologist, concluded for the diagnosis of Knuckle pads. When questioned about repetitive trauma of the fingers, he confessed having the habit of chewing the lesions on a regular basis, especially when anxious. He wasn't concerned about cosmetic issues. Recommendation to avoid the traumatic stimuli was made.

\section{Discussion}

Knuckle pads appear as slowly growing cutaneous thicken-

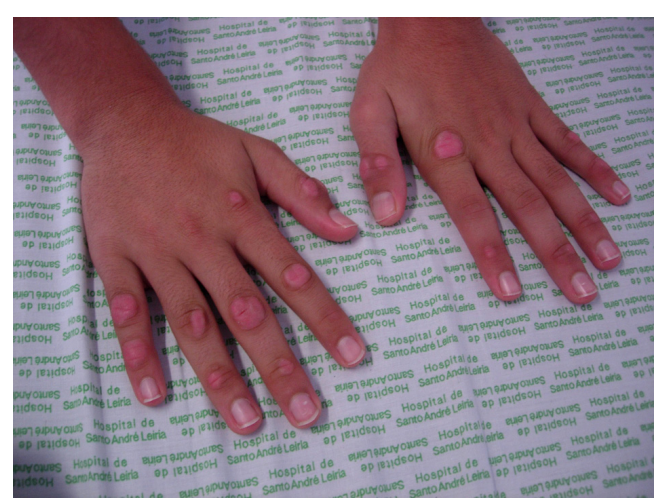

Figure 1. Knuckle pads overlying metacarpophalangeal, proximal interphalangeal and distal interphalangeal joints of both hands. 


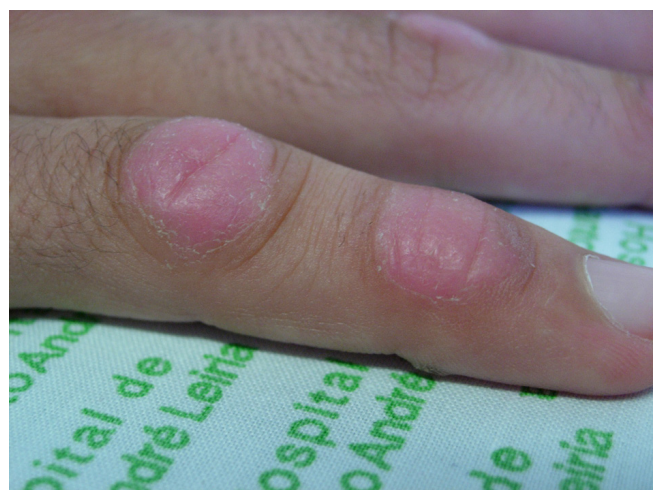

Figure 2. Well-circumscribed, non-tender, erythematous hyperkeratotic plaques varying in size between $0.5-1.8 \mathrm{~cm}$.

ings over the dorsal aspects of the digital joints [1]. They may be idiopathic or related to repetitive friction or pressure [2,3] like in our case report. Knuckle pads occur in association with several fibrosing diseases (Dupuytren's contracture, Ledderhose's syndrome and Peyronie's disease) and are part of the autosomal dominant Bart-Pumphrey syndrome [1]. The latter was excluded as there weren't palmoplantar hyperkeratosis or sensorineural deafness and familiar history was unremarkable. Knuckle pads may resolve spontaneously, especially when it's possible to identify and remove the causative repetitive traumatism $[2,3]$. However, most cases persist, are asymptomatic and don't require treatment [1]. Because Knuckle pads are benign, their importance lies in differentiating them from more significant cutaneous disorders [1]. Differential diagnosis comprises Gottron's papules, which share similar location [4]. Nevertheless, Gottron's papules present distinctive fea- tures (flat papules, erythematous/violaceous, with central atrophy), consisting on a cutaneous manifestation of Juvenile Dermatomyositis [4, 5]). Juvenile Dermatomyositis was excluded since our case report didn't fulfilled clinical criteria [5]: absence of typical skin rash and proximal muscle weakness and only mildly elevation of serum skeletal muscle enzymes (usually 5 to 20 times normal). The normal erythrocyte sedimentation rate also disfavored this diagnosis. Finally, differential diagnosis of Knuckle pads must also consider scars, granuloma annulare and rheumatoid nodules, among others [1].

\section{Conflict of Interest}

No conflict of interest for neither of the authors.

\section{References}

1. Paller AS, Hebert AA. Knuckle pads in children. Am J Dis Child. 1986;140(9):915-917.

2. Peterson CM, Barnes CJ, Davis LS. Knuckle pads: does knuckle cracking play an etiologic role? Pediatr Dermatol. 2000;17(6):450-452.

3. Dickens R, Adams BB, Mutasim DF. Sports-related pads. Int J Dermatol. 2002;41(5):291-293.

4. Garcia-Cruz A, Garcia-Doval I. Images in clinical medicine. Gottron's papules and dermatomyositis. N Engl J Med. 2010;363(12):e17.

5. Juvenile Dermatomyositis. In: Woo P, Laxer RM, Sherry DD, eds. Pediatric Rheumatology in Clinical Practice. 1st ed. London: Springer; 2007; 66-76. 